\title{
Impact of Automation Technology on Logistics and Supply Chain Management
}

\author{
Niraj Chaudhari \\ School of Management Studies, KBC North Maharashtra University, Jalgaon, India \\ Email address: \\ nirajchaudhari7@gmail.com

\section{To cite this article:} \\ Niraj Chaudhari. Impact of Automation Technology on Logistics and Supply Chain Management. American Journal of Theoretical and \\ Applied Business. Vol. 5, No. 3, 2019, pp. 53-58. doi: 10.11648/j.ajtab.20190503.12
}

Received: August 28, 2019; Accepted: September 23, 2019; Published: October 9, 2019

\begin{abstract}
Logistics and supply chain management not only includes activities related to the physical movements of the goods/ items but also management of relationship with suppliers and customers. However Logistic means fulfil the needs of customers are satisfaction through interface and coordination of the supply chain. The main objective of the paper is to determine the automation technology used in logistics and supply chain management including new technology like automation with automatic identification of materials and items. The paper also discusses the impact of the automation technology and challenge to implementing automation technology on logistics and supply chain management. The author mainly focuses on the both primary and secondary data for collecting data relating to various advance technology like automation used in logistics and supply chain management. The author draws conclusion that technology play important role to increased supply chain competitiveness and performance by effectiveness of logistics system.
\end{abstract}

Keywords: Logistics, Supply Chain Management, Automation Technology, Automatic Identification, Radio Frequency Identification

\section{Introduction}

Logistics consist study of supply chain process that planning, implementations, and controls the effective, forward and backward flow and storage of goods, services, and related data communications between the start point of origin to the end point of consumption in order to meet customer requirement". On the Other way we can be defined as right product, at the right place, in right time, and in right quality. However supply chain consists of all stages that are required to satisfy the customer needs. It starts from supplier passes through production house, distribution, and retailer and finally reaches the customer. The supply chain management is the process of materials, information and finances as they transfer from supplier to manufacturer to wholesaler to retailer to customer.

Now day's new technologies like automations are creating new opportunities for the industries to build competitive advantages in various areas of management including logistics and supply chain management. However the level of success depends on the implementation of the right technology for the application, availability of proper organizational infrastructure, culture and management policies. In logistics, information, communication and automation technologies has substantially increased speed of identification, data processing, analysis and transmission; with high accuracy. Technology is a means to enhance business competitiveness and performance. It plays a major role in success of supply chain by increasing the overall effectiveness and efficiency of the logistics system. In logistics many new technologies are used in developed country while in India adoption process is very slow so it is very important to study and work on such technology like automation for developments.

Objective of Study:

1. To determine automation technology used in logistics and supply chain management.

2. To discusses the impact of automation technology on logistics and supply chain management

\section{Automatic Identification Technology}

Automatic Identification (Auto ID) is the term used to the direct entry of data or information in the computer system, programmable logic controllers or any 
microprocessor-controlled device without manually operating. These technologies include Bar Coding, Radio Frequency Identification (RFID) and Voice Recognition. Auto ID can be used for tracking the containers, packages, cartons or a truck carrying the goods on time transportations dispatches to the customers. The benefits of Auto ID include accuracy, cost cutting, speed and easily of data storage and processing of information to systems.

The significant Automatic Identification technologies in use are.

\subsection{Bar Coding}

Bar coding is a sequence of parallel lines of different thickness with spaces in between. These bars are nothing but the items of information in the codified form, which can be read with the help of a scanner. The information printed in bar code consists, country code, manufacturer name, product details, date of manufacture, material content etc. These details are utilized at user end for inventory management. The bar codes are used in many industries such as pharmaceutical, big malls, consumer goods, electrical, manufacturing automobiles etc

\subsection{The Bar Coding Offers the Following Advantages}

1. Easy identification of inventory/stock items during storage, pickup, inspection and dispatch.

2. Reduce paper work / documentation and processing time leading.

3. Reduce human error.

4. Increases logistics system productivity through speed, accuracy and reliability.

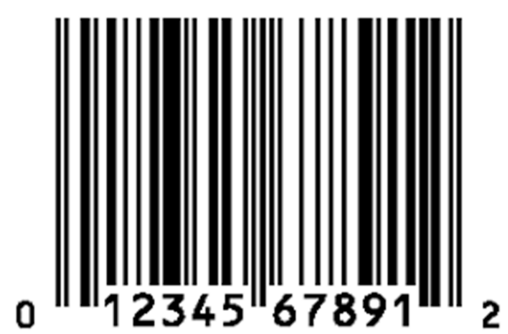

Figure 1. Barcode.

\subsection{Impact of Bar Code Technology on Operations of Logistics and Supply Chain Management}

1. Procurement-Materials from suppliers are assigned bar codes, which contain information on item name, batch number, date of manufacture, order no, serial no etc. The information in bar code helps in identifying and tracking the materials. In the warehouse, when the goods enter through a conveyor, they are further scanned by the hand held scanner or fixed scanner in conveyor. The information decoded by the scanner is immediately store in the central computer which helps real time update of inventory records.

2. Processing-During the order processing the bar code will help in keeping identification of items based on their date of entry into the warehouse or store. This will ease material storage and dispatch.

3. Production-During the production process the identification of in-process and finished items become easier due to bar coding. The various batches at different stages of production can be easily tracked.

4. Distribution-During distribution, barcode helps in identifying and tracking the transit of finished goods to the customers.

\section{Radio Frequency Identification (RFID)}

RFID is an Automatic Identification and Data Capture (AIDC) technology. RFID-based systems allow for non-contact reading and are effective in manufacturing and other environment where bar codes could not survive. This system utilized as alternative to Barcodes to the inventory data to the reader via radio waves. RFID wireless system in which exchanges information between a tagged object and a reader /receiver.

\subsection{An RFID System Is Compromised of the Following Components as Mentioned Below}

1. One or more tags called Radio Frequency Tags (RFTs), which includes a semiconductor chip and antenna.

2. One or more read/write devices also called readers.

3. Two or more antennas one on the tag and one on the reader.

4. Application software and the host computer system.

\subsection{Radio Frequency Tags (RFTs)}

The reader is connected to the central computer. Radio Frequency Tags (RFTs) is a small silicon Chip to store data in the microcircuit. The important operational function of tag is that antenna emits the radio signals. The tag will contain information such as inventory items, quantity and value, what time the item travelled from one placed to other. The reader receives the tag signal with help of its antenna and then decoding of data take placed and transfers the data to the host computer system. Due to RFTs will avoid paperwork and can be helpful in quick clearance at road tax systems and custom posts. In the warehouse, the barcodes use to the individual inventory materials and items while RFTs can be applied to pallets, containers etc. such a way staff to directly communicate to the warehouse computer.

\subsection{RFID has Significant Impact on Logistics and Supply Chain of Many Sectors}

1. Increased the ability of manufacturers to easily manage the inventory levels.

2. Increased the complex distribution system for the Defense operation.

3. Increased the complex tracking and distribution operations of the Indian Postal services.

4. Increased the tracking, logistics and planning operations of manufacturing industry. 
5. Implement automatic toll collection on network of highways.

\section{Impact Automation Technology on Logistics and Supply Chain Management Are as Follows}

\subsection{Procurement}

In the initial period the procurement process in the organization was done by a separate department on the basis of least price from the supplier. Now a day with the help of automation the E-procurement is done where online process is conducted and strategic relations are forged with good suppliers by long term contracts and relationships.

\subsection{Planning}

In the initial period before the use of automation technology, production and distribution planning was done based on historical data. There was not most useful with business planning and production changed with demand. However with help of IT planning approach include planning, forecasting.

\subsection{Web-based Collaboration}

The web-based collaboration use as sharing and collaborating with supply chain partners on future planning and promotions plans to deliver the highest level of customer satisfaction by service and profitability.

\subsection{Scheduling}

initially the scheduling was done to improve asset utilization and reduce manufacturing costs. However with the help of automation strong linkage is established between supply chain partners and customers. Proper scheduling is done to serve the customer at the right time.

\subsection{Inventory Management}

In the initial period every department tried to minimize the inventory by movement of material and items to next level of the supply chain. Thus the total inventory cost in the supply chain was high as there was no clear idea of the inventory held in the supply chain. However with the help of automation and information technology, techniques such as collaborative and vendor management inventory were followed where manufacturer takes the responsibility to the distributor inventory, resulting in inventory control and access to demand information.

\subsection{Logistics and Warehouse Management}

Initially period logistics was more manual documentation and there was no visibility of the movement of items. However due to help of automation and technologies like GPS complete visibility in movement of goods is available so result in efficient logistic and warehouse management.

\subsection{Customer Service}

In the initial time customer service was only reactive approach. The problems in information were difficult to reach the proper department and were time consuming system. However with using automation, customer service is easier as it reaches the customer through internet and takes continuous feedback from them.

\section{Benefits of Logistics Automation}

\subsection{Automated Goods in Processes}

Incoming goods can be marked with barcodes and the automation system notified of the expected stock. On arrival, the goods can be scanned and thereby identified, and taken via conveyors, sortation systems, and automated cranes into an automatically assigned storage location.

\subsection{Automated Goods Retrieval for Orders}

On receipt of orders, the automation system is able to immediately locate goods and retrieve them to a pick-face location.

\subsection{Automated Dispatch Processing}

Combining knowledge of all orders placed at the warehouse the automation system can assign picked goods into dispatch units and then into outbound loads. Sortation systems and conveyors can then move these onto the outgoing trailers

\section{Benefits of Supply Chain Management Automation}

\subsection{Decreasing Operating Costs}

Supply chain automation helps in the reduction of labor costs, inventory, warehousing, and overhead costs associated with inventory storage, including rent, labor and energy costs.

\subsection{Increasing Productivity}

By optimizing current resources, enabling around the clock work, companies can gain up to 20 percent more productivity in areas that have been automated.

\subsection{Increasing Volume}

For manufacturers, automation allows for the increase of the volume of products that can be produced. The technology will allow for the incorporation of the skills of trained workers with the accuracy of automated equipment, hence, increasing productivity.

\subsection{Improving Accuracy}

Automation can reduce errors associated with manual processes, which in turn, helps plan cost control through providing accurate, real-time information on inventory levels. 


\subsection{Improving Time Savings}

Through streamlining business processes, supply chain automation boosts time savings by reducing the time associated with implementing labor intensive tasks like accounting, saving manufacturers immense amount of time and money.

\subsection{Integrating with Large Suppliers}

The ability to integrate systems with that of large suppliers is one of the major advantages of automating a supply chain, as it enables a strong foundation of which permits more visibility between partners.

\subsection{Improving Compliance}

Automation can assist organizations with complying with industry standards through standardizing pricing, products and vendors.

\section{Challenges in Implementation Automation in Supply Chain \& Logistics}

Any company that has undertaken the mission of implementing an integrated supply chain management strategy with the use of IT tools knows that one of the greatest challenges it faces is the significant change in internal culture that is required to make the supply chain redesign successful. It is difficult to re-condition people to accept change where a certain mindset has prevailed for many years. However it may be difficult to accomplish, change can be successfully implemented when directed by a knowledgeable and strong leader, who knows the tools available for achieving positive change, as well as their contribution in initiating and sustaining these changes. Integrating new applications with existing and legacy systems could also pose problems. Incompatible systems at buyer and vendor facilities are another management challenge to tackle. Data sharing with diverse stakeholders like suppliers and customers, filtering and mining data generated and finding "business" value of the data are other issues. Disconnected enterprise systems create data redundancy, errors and can lead to costly business inefficiencies. Poor coordination between enterprise systems leads to flawed production plans, increased supply chain pressure and poor customer service. Lack of visibility of orders, schedules and shipments can lead to costly administrative decision making processes.

\section{Research Methodology of the Study}

The study is based on critical evaluation and analysis of basically Primary Data. The primary sources include industrial personnel which are on working with logistics and supply chain management department of industries.

With the help of the questionnaire, detailed discussions were made with the certain sources of primary data to understand their views, thinking and attitude which would help to give the researchers useful recommendations, if any. The questionnaire is processed with the help of statistical tools like tabulations, grouping, percentages, growth rate, averages, etc. Questionnaire is used mainly to analyze the opinion of the industrial personnel.

\subsection{Why Survey Among Industrial Personnel's}

Industrial Development is very important in any country economy and increasing employment when we study about industrialization related factors like Supply chain Management \& Logistics and its impact factors, so for that it is very important to consider opinion of industrial personnel which is involve in this research area field.

\subsection{Research Area}

Researchers' selected small scale and Large scale Industries from Jalgaon district in Maharashtra state of India as pilot study for this research paper. Researcher selected 40 small scale industries and 08 large scale industries in Jalgaon district Researcher collects data through Primary and Secondary sources. Researcher distributes questionnaires among the Industrial personnel which is Plant manager, Production manager, Maintenance manager and Purchase manager in each industry.

\subsection{Data Analysis}

Researcher prepared the questionnaire for Industrial personnel and distributes it among the Industrial personnel Plant manager, Production manager, Purchase manager \& Maintenance manager in each industry total 48 industry. In which 40 are small scale industries and 08 large scale industries. After receiving the questionnaire researcher analysis the questionnaire and make four groups of Plant manager, Production manager, Maintenance manager and Purchase manager in each industry.

Table 1. Information of questionnaire.

\begin{tabular}{|c|c|c|c|c|c|}
\hline Types of Industries & Plant Manager & Production Manager & Maintenance Manager & Purchase Manager & Total \\
\hline Small Scale & 40 & 40 & 40 & 40 & 160 \\
\hline Large Scale & 08 & 08 & 08 & 08 & 32 \\
\hline Total & 48 & 48 & 48 & 48 & 192 \\
\hline
\end{tabular}

There are 160 questionnaire received from small scale industries and 32 from large scale industries, after analysis, Finally researcher select $100 \%$ respondents i.e. 192 for study purpose.

\subsection{Testing of Hypothesis}

$\mathrm{H}_{0}$ : There is proportion of industries whose perception 
about Impact of Automation Technology on Logistics and Supply Chain Management is positive is 0.50 .

$\mathrm{H}_{1}$ : There is proportion of industries whose perception about Impact of Automation Technology on Logistics and Supply Chain Management is positive is more than 0.50 .

Mathematically here level of significance is 0.50 .

Chi-square formula for testing hypothesis is as follow:

$$
\mathrm{X}^{2}=\sum_{\mathrm{i}} \sum_{\mathrm{j}}\left(\mathrm{O}_{\mathrm{il}}-\mathrm{E}_{\mathrm{ij}}\right)^{2} / \mathrm{E}_{\mathrm{ij}}
$$

While applying the Formula. Following two tables were prepared.

Table 2. Respondent Opinion.

\begin{tabular}{llll}
\hline Designation Of Respondent & YES & NO & Total \\
\hline Plant Manager & 37 & 11 & 48 \\
Production Manager & 33 & 15 & 48 \\
Purchase Manager & 31 & 17 & 48 \\
Maintenance Manager & 27 & 21 & 48 \\
Total & 128 & 64 & 192 \\
\hline
\end{tabular}

Table 3. Testing Of Hypothesis.

\begin{tabular}{lllll}
\hline Oij & $\mathbf{E i j}$ & $\mathbf{O} \mathbf{i j - E i j}$ & $(\mathbf{O i j}-\mathbf{E i j})^{\mathbf{2}}$ & $(\mathbf{O} \mathbf{i j}-\mathbf{E i j})^{\mathbf{2}} / \mathbf{E i j}$ \\
\hline 37 & 32 & 5 & 25 & 0.78 \\
33 & 32 & 1 & 1 & 0.03 \\
31 & 32 & -1 & 1 & 0.03 \\
27 & 32 & -5 & 25 & 0.78 \\
11 & 16 & -5 & 25 & 1.56 \\
15 & 16 & -1 & 1 & 0.06 \\
17 & 16 & 1 & 1 & 0.06 \\
21 & 16 & 5 & 25 & 1.56 \\
& & & Total & 4.86 \\
\hline
\end{tabular}

Thus From the above we have calculated value of $\mathrm{X}^{2}$ is 4.86 .

Now, Critical Value of $\mathrm{X}^{2}$ Statistic for $(\mathrm{m}-1)(\mathrm{n}-1)$ is denoted by $\mathrm{X}_{(\mathrm{m}-1)(\mathrm{n}-1)}$.

Where $(m-1)(n-1)$ are degree of freedom i.e. (4-1) $(2-1)=3$

The table value at $5 \% 1$. o. s. is 7.815 .

Thus, the observed value $\mathrm{X}_{0}^{2}>\mathrm{X}^{2}{ }_{3: 0.05}$.

Hence, reject $\mathrm{H}_{0}$, and accept $\mathrm{H}_{1}$.

Therefore, there is proportion of industries whose perception about Impact of Automation Technology on Logistics and Supply Chain Management is positive is more than 0.50 .

\section{Conclusion}

Automation technology increased supply chain competitiveness and performance by enhancing the overall effectiveness and efficiency of logistics system. Hence choosing the right technology for various logistics and supply chain activities or sub-processes is very important to any business to gain competitive advantage in today's competitive market. at conclude state suggestion after doing study it is very important to implementation of new advanced technology like automation in supply chain management and logistics it is very useful for smooth operation process of every industries and future development.

\section{References}

[1] J.-F., Saslavsky, D., Ojala, L., Shepherd, B., Busch, C. and Raj, A. (2014), Connecting to Compete 2014: Trade Logistics in the Global Economy, The World Bank: Washington, DC.

[2] Asian Development Bank (2014), Asian Development Outlook 2014: Fiscal Policy for Inclusive Growth, Asian Development Bank: Metro Manila, Philippines.

[3] Chang, H. H., Tsai, Y. C., \& Hsu, C. H. (2013). E-procurement and supply chain performance. Supply Chain Management: An International Journal, 18 (1), pp. 34-51.

[4] Boas, J., Carvalho, J. and Henrique, N. (2014), "Logistics and Supply Chain Management: An Area with a Strategic Service Perspective", American Journal of Industrial and Business Management, Vol. 4, No. 1, pp. 24-30.

[5] Hoejmose, S., Brammer, S. and Millington, A. (2012), “Green supply chain management: The role of trust and top management in B2B and B2C markets", Industrial Marketing Management, Volume 41, pp. 609-620

[6] Dubey, R., \& Samar Ali, S. (2013). An exploratory study on logistics competency and firm performance. International Journal of Logistics Systems and Management, 14 (2), pp. 179-199.

[7] Randall, W. S., \& Mello, J. E. (2012). Grounded theory: an inductive method for supply chain research. International Journal of Physical Distribution \& Logistics Management, 42 (8/9), pp. 863-880.

[8] Johanson, J. and Mattsson, L. G. (1987), "Interorganizational relations in industrial systems: a network approach compared with the transaction cost approach", Inter-Organizational Studies of Management and Organization, Vol. 17 No. 1, pp. 34-48

[9] Mabert, V. A., Venkataramanan, M. A., (1998) "Special research focus on supply chain linkages: challenges for design and management in the 21st century". Decision Sciences 29 (3), pp. $537-552$.

[10] Williamson, O. E. (2007). The Economic Institutions of Capitalism. Firms, Markets, Relational Contracting. In Das Summa Summarum des Management (pp. 61-75). Gabler.

[11] Steve V. Walton, J. N. (1999). Electronic data interchange for process change in an integrated supply chain. International Journal of Operations \& Production Management, 19 (4), pp. 372-388.

[12] Rahman, Z. (2003), "Internet-based supply chain management: using the Internet to revolutionize your business", International Journal of Information Management, Volume 23, pp. 493-505. KA Stouffer, JA Falco and KA Scarfone, SP 800-82 Guide to Industrial Control Systems (ICS) Security: Supervisory Control and Data Acquisition (SCADA) systems, Distributed Control Systems (DCS), and Other Control System Configurations such as Programmable Logic Controllers (PLC), Technical report, National Institute of Standards \& Technology.

[13] M. E. Sobel, (1992) "Asymptotic confidence intervals for indirect effects instructural equation models," Sociological Methodology, vol. 13, pp. 290-312.

[14] T. C. Tan, S. B. Lyman, and J. D. Wisner, (2002) "Supply chain management: a strategic perspective," International Journal of Operations \&Production Management, vol. 22, no. 6, pp. 614-31. 
[15] A. Wong, D. Tjosvold, W. Y. L. Wong, and C. K. Liu, (1999) "Relationships for quality improvement in the Hong Kong-China supply chain," The International Journal of Quality \& Reliability Management, vol. 16, no. 1, pp. 24-4.

[16] D. P. MacKinnon, C. M. Lockwood, M. Hoffman, S. G. West, and V. Sheets, (2002) "A comparison of methods to test mediation and other intervening variable effects," Psychological.

[17] S. Li, S. S. Rao, T. R. Nathan, and B. R. Nathan, (2005) "Development and validation of a measurement instrument for studying supply chain management practices," Journal of Operations Management, vol. 23 no. 6, pp. 618-4.

[18] C. Forza, (1996) "Work organization in lean production and traditional plants," International Journal of Operations \& Production Management, vol. 16, no. 2, pp. 42-62.

[19] Y. J. Chen, S. Seshadri, and E. Zemel, (2008) "Sourcing through auctions and audits," Production and Operations Management, vol. 17, no. 2, pp. 121-138.

[20] Y. Wei and T. M. Choi, (2010) "Mean-variance analysis of supply chains under wholesale pricing and profit sharing schemes," European Journal of Operational Research, vol. 204, no. 2 , pp. $255-262$.
[21] A. G. Kok and Y. Xu, (2011) "Optimal and competitive assortments " with endogenous pricing under hierarchical consumer choice models," Management Science, vol. 57, no. 9, pp. $1546-1563$.

[22] K. Inderfurth and I. M. Langella, (2006) "Heuristics for solving disassemble-to-order problems with stochastic yields," OR Spectrum, vol. 28, no. 1, pp. 73-99.

[23] K. Inderfurth, (2005) "Impact of uncertainties on recovery behavior in a remanufacturing environment: a numerical analysis," International Journal of Physical Distribution and Logistics Management, vol. 35, no. 5, pp. 318-336.

[24] M. Denizel, M. Ferguson, and G. C. Souza, (2010) "Multiperiod remanufacturing planning with uncertain quality of inputs," IEEE Transactions on Engineering Management, vol. 57 , no. 3 , pp. $394-404$

[25] S. Croom, P. Romano, and M. Giannakis, (2000) "Supply chain management: an analytical framework for critical literature review," European Journal of Purchasing and Supply Management, vol. 6, no. 1, pp. 67-83.

[26] W. T. Huh and G. Janakiraman, (2008) "Inventory management with auctions and other sales channels: optimality of (s, S) policies," Management Science, vol. 54, no. 1, pp. 139-150. 